\title{
Critical Cooling Rate for the Glass Formation of Ferromagnetic
}

\section{$\mathrm{Fe}_{80} \mathrm{P}_{13} \mathrm{C}_{7}$ Alloy}

Kai $X U^{1)}$, Yan $W A N G^{1)}$, Jinfeng $L I^{1)}$ and Qiang $L I^{1,2) \dagger}$

1) School of Physics Science and Technology, Xinjiang University, Urumqi 830046, China

2) State Key Laboratory of Powder Metallurgy, Central South University, Changsha 410083, China

[Manuscript received 9 July 2012, in revised form 29 September 2012]

(c) The Chinese Society for Metals and Springer-Verlag Berlin Heidelberg

\begin{abstract}
In this paper the critical cooling rate, $R_{\mathrm{C}}$, for the glass formation of $\mathrm{Fe}_{80} \mathrm{P}_{13} \mathrm{C}_{7}$ alloy has been determined using both Uhlmann's and Barandiaran-Colmenero's method. In Uhlmann's method, all kinds of the expressions of $\Delta G^{\mathrm{l}-\mathrm{s}}(T)$ and $\eta(T)$ determined using the different modes and methods had been investigated. It is indicated that the $R_{\mathrm{c}}$ for the glass formation of $\mathrm{Fe}_{80} \mathrm{P}_{13} \mathrm{C}_{7}$ alloy can be estimated to be $349 \mathrm{~K} / \mathrm{s}$ by Uhlmann's method based on the appropriate expressions of $\Delta G^{\mathrm{l}-\mathrm{s}}(T)$ and $\eta(T)$. The calculated result accords with our experimental result. The $R_{\mathrm{c}}$ for the glass formation of $\mathrm{Fe}_{80} \mathrm{P}_{13} \mathrm{C}_{7}$ alloy has also been determined to be $0.49 \mathrm{~K} / \mathrm{s}$ using Barandiaran-Colmenero's method. This resultant $R_{\mathrm{c}}$ is unreasonable low and it indicates that BarandiaranColmenero's method does not suit to Fe-based alloy.
\end{abstract}

KEY WORDS: Glass formation ability; Critical cooling rate; $\mathrm{Fe}_{80} \mathrm{P}_{13} \mathrm{C}_{7}$ alloy

\section{Introduction}

$\mathrm{Fe}_{80} \mathrm{P}_{13} \mathrm{C}_{7}$ alloy is the first magnetic amorphous alloy and was first synthesized by Duwez and Lin ${ }^{[1]}$. This alloy has excellent soft magnetic properties and had been extensively studied for the subsequently several decades. The critical cooling rate, $R_{\mathrm{c}}$, for the glass formation of this alloy had been estimated in many references and until now the lowest one was $\sim 1.8 \times 10^{4} \mathrm{~K} / \mathrm{s}^{[2]}$. It was generally believed that this alloy cannot be prepared in a bulk amorphous form due to low glass forming ability. However, more recently, the bulk magnetic $\mathrm{Fe}_{80} \mathrm{P}_{13} \mathrm{C}_{7}$ glassy alloy rods with a maximum diameter of $\sim 2.0 \mathrm{~mm}$ was prepared by the combination method of fluxing technique and J-quenching technique ${ }^{[3]}$. The corresponding $R_{\mathrm{c}}$ for the glass formation of this alloy is estimated to be below $10^{3} \mathrm{~K} / \mathrm{s}^{[4]}$. Thus it is necessary to re-estimate the $R_{\mathrm{c}}$ for the glass formation of $\mathrm{Fe}_{80} \mathrm{P}_{13} \mathrm{C}_{7}$ alloy.

$R_{\mathrm{c}}$ is the lowest cooling rate for solidifying the liquid of a glass-forming material without crystallization. A number of methods have been devised to determine $R_{\mathrm{c}}$. The most common method is to construct

† Corresponding author. Prof., Ph.D.; Tel: +86 9918583183 Fax:+86 991 8582404; E-mail address: qli@xju.edu.cn (Qiang LI)

DOI: $10.1007 / \mathrm{s} 40195-012-0117-1$ time-temperature-transformation (TTT) curve for the evaluation of $R_{\mathrm{c}}$ based on homogeneous nucleation mechanism developed by Uhlmann ${ }^{[5]}$. Improvement for this method to get a more realistic estimate of $R_{\mathrm{c}}$ is to construct continuous-cooling-transformation (CCT) curve instead of TTT curve. This type of calculation has been successfully applied to many glassforming systems ${ }^{[6,7]}$. However in order to implement Uhlmann's method, the temperature dependences of many thermal parameters in the undercooled region of alloy, such as the difference of molar Gibbs free energy between liquid and solid $\Delta G^{\mathrm{l}-\mathrm{s}}$, viscosity $\eta$ and so on, are required. But the metastable nature of the undercooled phase makes it difficult to obtain these thermal parameters of the alloy experimentally. Only for Zr-based and Pd-based alloys which have a relative large stability in the undercooled region, the numerous thermodynamic data had been obtained experimentally. As a result, the $R_{\mathrm{c}}$ for the glass formation of Zr-based and Pd-based alloys can be calculated by Uhlmann's method and the resultant results well accord with actual situation. But for Fe-based alloy, due to lack of data for thermal parameters in the undercooled region, it is difficult to obtain reliable $R_{\mathrm{c}}$ for the glass formation by Uhlmann's method.

Besides Uhlmann's method, the $R_{\mathrm{c}}$ for the glass formation can also be experimentally estimated from 
measurements on cooling rate dependence of the offset temperature for fusion and the onset temperature of solidification using differential thermal analysis (DTA) developed by Barandiaran and Colmenero ${ }^{[8]}$. Compared with Uhlmann's method, BarandiaranColmenero's method is simple, and none predetermined parameters are required. However the validity of this method for Fe-based amorphous alloys needs to be verified.

In this paper, the determination of $R_{\mathrm{c}}$ for the glass formation for $\mathrm{Fe}_{80} \mathrm{P}_{13} \mathrm{C}_{7}$ alloy by both Uhlmann's and Barandiaran-Colmenero's methods is presented. Because of lacking experimental data, some theoretical models have to be employed during calculation in order to give the temperature dependences of the required thermal parameters in the undercooled region of $\mathrm{Fe}_{80} \mathrm{P}_{13} \mathrm{C}_{7}$ alloy, and all kinds of theoretical models of difference of Gibbs free energy between liquid and solid $\Delta G^{\mathrm{l}-\mathrm{s}}(T)$ and viscosity $\eta(T)$ in the undercooled region of $\mathrm{Fe}_{80} \mathrm{P}_{13} \mathrm{C}_{7}$ alloy have been examined also. The main purpose of this work is to reveal which methods and theoretical models are suitable to be employed for determining $R_{\mathrm{c}}$ for the glass formation of Fe-based alloy by checking whether the obtained results are rational.

\section{Calculation Methods for $R_{\mathrm{c}}$ for the Glass Formation of $\mathrm{Fe}_{80} \mathrm{P}_{13} \mathrm{C}_{7}$ Alloy}

\subsection{Uhlmann's method}

Along with Uhlmann's method, the TTT curve of the alloy can be constructed based on homogenous nucleation mechanism.

When the volume fraction of the crystallized material $X$ in an undercooled liquid alloy is small, $X$ can usually be described very well by the Johnson-MehlAvrami equation:

$$
X=\frac{\pi}{3} I_{\mathrm{s}} U^{3} t^{4}
$$

where $I_{\mathrm{S}}$ is the steady-state nucleation frequency, $U$ is the crystal growth velocity, and $t$ is the time taken for $X$ to appear.

The $I_{\mathrm{s}}$ can be written as ${ }^{[9]}$

$$
I_{s}=\frac{8 n^{* 2 / 3} N_{A} k_{\mathrm{B}} T}{\eta(T) a_{0}^{3} V_{m}} Z \exp \left(-\frac{\Delta G_{n}^{*}}{k_{B} T}\right)
$$

where $\eta(T)$ is the viscosity of molten alloy, $a_{0}$ is the atomic jump distance, $V_{\mathrm{m}}$ is the molar volume, $k_{\mathrm{B}}$ is the Boltzman constant, $T$ is the temperature, and $N_{\mathrm{A}}$ is the Avogadro's number. To evaluate some of these parameters, the density of the bulk amorphous $\mathrm{Fe}_{80} \mathrm{P}_{13} \mathrm{C}_{7}$ alloy has been measured by means of immersed water method at room temperature. It is equal to $7.51 \times 10^{3} \mathrm{~kg} / \mathrm{m}^{3}$. For simplicity, the temperature dependence of the density is ignored. And the molar mass of $\mathrm{Fe}_{80} \mathrm{P}_{13} \mathrm{C}_{7}$ alloy is $49.55 \times 10^{-3} \mathrm{~kg} / \mathrm{mol}$. Thus it can be deduced that $V_{\mathrm{m}}=6.60 \times 10^{-6} \mathrm{~m}^{3}$ and $a_{0}=0.223 \mathrm{~nm}$. The factor $Z$ is called the Zeldovich factor and in most cases, $0.01<Z<0.1$. Here $Z=0.05$ is chosen.

$n^{*}$ is the critical cluster size and is given by

$$
n^{*}=\frac{32 N_{A} \pi}{3 V_{m}} \frac{\sigma^{3}}{\left|\Delta G_{V}^{3}\right|}
$$

where $\Delta G_{\mathrm{V}}$ is the Gibbs free energy difference from the liquid phase and the solid phase per unit volume and can be expressed as $\frac{\Delta G^{1-\mathrm{s}}}{V_{\mathrm{m}}}$ where $\Delta G^{\mathrm{l}-\mathrm{s}}$ is the molar Gibbs free energy difference from the liquid phase and the solid phase, $\sigma$ is the interface energy between the solid phase and liquid phase per unit area.

$\Delta G_{n^{*}}$ is the nucleation barrier for the formation of the critical nucleus and is given by

$$
\Delta G_{n *}=\frac{16 \pi}{3} \frac{\sigma^{3}}{\Delta G_{V}^{2}}
$$
by ${ }^{[10}$

The crystal growth velocity $U$ can be expressed

$$
U=\frac{f k_{\mathrm{B}} T}{3 \eta(T) a_{0}^{3}}\left[1-\exp \left(-\frac{\Delta G^{\mathrm{l}-\mathrm{s}}}{k_{\mathrm{B}} T}\right)\right]
$$

where $f$ is the fraction of sites on the interface where atoms may preferentially be added and removed. For metallic materials, $f$ can be expressed as $f=$ $0.2 \Delta T_{\mathrm{r}}{ }^{[5]}$, where $\Delta T_{\mathrm{r}}$ is the reduced undercooling and defined as $\frac{T_{\mathrm{m}}-T}{T_{\mathrm{m}}}$ where $T_{\mathrm{m}}$ is the melting temperature.

The overall transformation kinetics of the amorphous alloy can be constructed if all parameters in the above equations such as $\Delta G^{\mathrm{l}-\mathrm{s}}, \sigma, \eta(T)$ and so on can be determined.

\subsubsection{Estimation of the difference of Gibbs free energy between solid and liquid}

The Gibbs free energy difference between the liquid and crystalline phases is given by

$$
\Delta G^{\mathrm{l}-\mathrm{s}}=\Delta H^{\mathrm{l}-\mathrm{s}}-T \Delta S^{\mathrm{l}-\mathrm{s}}
$$

where

$$
\begin{gathered}
\Delta H^{\mathrm{l}-\mathrm{s}}=\Delta H_{\mathrm{m}}-\int_{T}^{T_{\mathrm{m}}} \Delta C_{P}^{\mathrm{l}-\mathrm{s}} d T \\
\Delta S^{\mathrm{l}-\mathrm{s}}=\Delta S_{\mathrm{m}}-\int_{T}^{T_{\mathrm{m}}} \frac{\Delta C_{P}^{\mathrm{l}-\mathrm{s}}}{T} d T
\end{gathered}
$$

where $\Delta S_{\mathrm{m}}$ and $\Delta H_{\mathrm{m}}$ are the molar entropy and the enthalpy of fusion of the alloy and they are related to each other by the equation of $\Delta H_{\mathrm{m}}=T_{\mathrm{m}} \Delta S_{\mathrm{m}}$. $\Delta C_{P}^{\mathrm{l}-\mathrm{s}}$ is the difference in specific heats of liquid phase and crystalline phase. In the case of the nonavailability of $\Delta C_{P}^{\mathrm{l}-\mathrm{s}}$, some approximated theoretical models have been proposed and results in the different expressions for $\Delta G^{\mathrm{l}-\mathrm{s}}$.

At first $\Delta C_{P}^{\mathrm{l}-\mathrm{s}}$ is frequently assumed to be a constant under condition of a small undercooling. So $\Delta G^{\mathrm{l}-\mathrm{s}}$ can be written as 


$$
\begin{aligned}
& \Delta G^{\mathrm{l}-\mathrm{s}}=\frac{\Delta H_{\mathrm{m}}\left(T_{\mathrm{m}}-T\right)}{T_{\mathrm{m}}}+ \\
& \Delta C_{P}^{\mathrm{l}-\mathrm{s}}\left(T \ln \frac{T_{\mathrm{m}}}{T}-T_{\mathrm{m}}+T\right)
\end{aligned}
$$

Hoffman $^{[11]}$ had chosen the temperature $T_{\alpha}$ at which $\Delta H^{\mathrm{l}-\mathrm{s}}=0$. Assuming $T_{\alpha} \ll T_{\mathrm{m}}$, Eq. (9) can be simplified as

$$
\Delta G^{\mathrm{l}-\mathrm{s}}=\Delta H_{\mathrm{m}} \frac{\left(T_{\mathrm{m}}-T\right) T}{T_{\mathrm{m}}^{2}}
$$

Thompson and Spaepen ${ }^{[12]}$ had chosen the temperature $T_{0}$ at which $\Delta S^{\mathrm{l}-\mathrm{s}}=0$ and thus gave $\Delta C_{P}^{\mathrm{l}-\mathrm{s}}=$ $\frac{\Delta H_{\mathrm{m}}}{T_{\mathrm{m}}}$. For further simplification, the following approximation was used:

$$
\ln \frac{T_{\mathrm{m}}}{T} \approx \frac{2\left(T_{\mathrm{m}}-T\right)}{T_{\mathrm{m}}+T}
$$

Substituting $\Delta C_{P}^{\mathrm{l}-\mathrm{s}}=\frac{\Delta H_{\mathrm{m}}}{T_{\mathrm{m}}}$ and the above equation into Eq. (9), $\Delta G^{\mathrm{l}-\mathrm{s}}$ can be expressed as

$$
\Delta G^{\mathrm{l}-\mathrm{s}}=\frac{\Delta H_{\mathrm{m}} \times 2 \times\left(T_{\mathrm{m}}-T\right) T}{T_{\mathrm{m}}\left(T_{\mathrm{m}}+T\right)}
$$

Along the method of Thompson and Spaepen's, Lad et al. ${ }^{[13]}$ use more strictly approximation as the following:

$$
\ln \frac{T_{\mathrm{m}}}{T} \approx 2 \times\left[\frac{T_{\mathrm{m}}-T}{T_{m}+T}+\frac{1}{3}\left(\frac{T_{\mathrm{m}}-T}{T_{\mathrm{m}}+T}\right)^{3}\right]
$$

Substituting the above equation into Eq. (9), $\Delta G^{\mathrm{l}-\mathrm{s}}$ can be written as

$$
\Delta G^{\mathrm{l}-\mathrm{s}}=\frac{\Delta H_{\mathrm{m}} \times 2 \times\left(T_{\mathrm{m}}-T\right) T}{T_{\mathrm{m}}\left(T_{\mathrm{m}}+T\right)}\left[1+\frac{\left(T_{\mathrm{m}}-T\right)^{2}}{3\left(T_{\mathrm{m}}+T\right)^{2}}\right]
$$

Besides assuming $\Delta C_{\mathrm{P}}^{\mathrm{l}-\mathrm{s}}$ to be a constant, Ji and $\operatorname{Pan}^{[14]}$ proposed $\Delta C_{P}^{\mathrm{l}-\mathrm{s}}=\frac{\Delta H_{\mathrm{m}}}{T}$ based on the experimental data of $\Delta C_{\mathrm{p}}^{\mathrm{l}-\mathrm{s}}$ of $\mathrm{Zr}_{57} \mathrm{Cu}_{15.4} \mathrm{Ni}_{12.6} \mathrm{Al}_{10} \mathrm{Nb}_{5}$ alloy. So $\Delta G^{\mathrm{l}-\mathrm{s}}$ can be expressed as

$$
\begin{gathered}
\Delta G^{\mathrm{l}-\mathrm{s}}=\frac{2 \times \Delta H_{\mathrm{m}}\left(T_{\mathrm{m}}-T\right)}{T_{\mathrm{m}}} . \\
{\left[\frac{T}{T+T_{\mathrm{m}}}-\frac{T_{\mathrm{m}}\left(T_{\mathrm{m}}-T\right)^{2}}{3\left(T_{\mathrm{m}}+T\right)^{3}}\right]}
\end{gathered}
$$

$\Delta H_{\mathrm{m}}$ of $\mathrm{Fe}_{80} \mathrm{P}_{13} \mathrm{C}_{7}$ alloy is $10.6 \mathrm{~kJ} / \mathrm{mol}$ determined from DTA curve. So the function curves of $\Delta G^{\mathrm{l}-\mathrm{s}}(T)$ for $\mathrm{Fe}_{80} \mathrm{P}_{13} \mathrm{C}_{7}$ alloy obtained using from Eq. (10) to Eq. (13) are shown in Fig.1.

\subsubsection{Estimation of the interfacial free energy of the solid/liquid interface}

The interfacial free energy of the solid/liquid interface, $\sigma$, according to the broken-bond model, can be written as ${ }^{[15]}$

$$
\sigma=\alpha \frac{\Delta H_{\mathrm{m}}}{\left(N_{\mathrm{A}} V_{\mathrm{m}}^{2}\right)^{1 / 3}}
$$

where $\alpha$ is the packing factor for the given structure. For the glass formation alloys the nucleation barrier

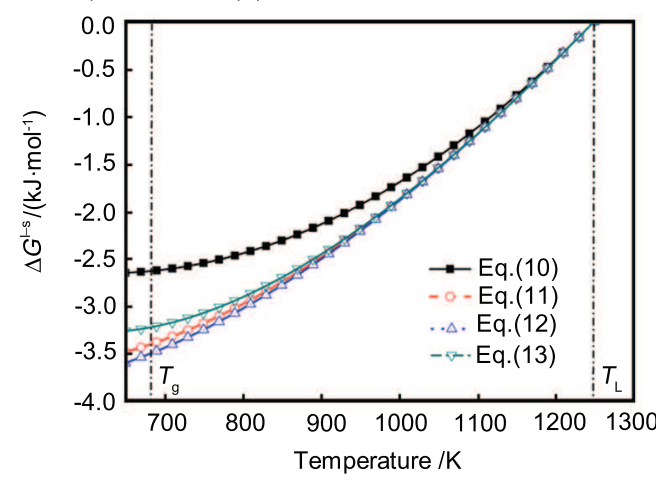

Fig. 1 The relationship between $T$ and $\Delta G^{1-\mathrm{s}}$ for $\mathrm{Fe}_{80} \mathrm{P}_{13} \mathrm{C}_{7}$ alloy determined by the different expressions

$\Delta G_{n^{*}}$ is about $60 k_{\mathrm{B}} T$ at $\Delta T_{\mathrm{r}}=0.2$. Thus $\alpha$ can be assumed to have a value of 0.41 .

\subsubsection{Estimation of the viscosity of $\mathrm{Fe}_{80} \mathrm{P}_{13} \mathrm{C}_{7}$ alloy}

In order to construct TTT curve, the temperature dependence of the viscosity $\eta$ of $\mathrm{Fe}_{80} \mathrm{P}_{13} \mathrm{C}_{7}$ alloy will be required. However, such knowledge is not available at present and the estimation has to be carried out.

The estimation of the viscosity $\eta$ of $\mathrm{Fe}_{80} \mathrm{P}_{13} \mathrm{C}_{7}$ alloy is based on the widely accepted Vogel-Fulcher's equation:

$$
\eta(T)=A \exp \left(\frac{B}{T-T_{0}}\right)
$$

where $A, B$ and $T_{0}$ are constants. $A, B$ and $T_{0}$ need to be determined in order to obtain the expression of the viscosity $\eta$.

Chen ${ }^{[16,17]}$ and other workers ${ }^{[18-20]}$ have shown that the apparent activation energies, $E(T)$, for glass transition and crystallization in some metallic and oxide glasses coincide with those for viscous flow. This coincidence implies that both the rates of the glass transition and crystallization in metallic glass scale as that of viscosity. The apparent activation energies for viscous flow as a function of temperature are given by

$$
E(T)=R \frac{\mathrm{d}(\ln (\eta))}{\mathrm{d}(1 / T)}=\frac{R B T^{2}}{\left(T-T_{0}\right)^{2}}
$$

So the apparent activation energies for the glass transition $\left(E_{\mathrm{g}}\right)$ and crystallization $\left(E_{\mathrm{p}}\right)$ can be obtained by using the Kissinger plot ${ }^{[21]}$ :

$$
\ln \left(\frac{T_{\mathrm{g}}^{2}}{\phi}\right)=\frac{E_{\mathrm{p}}}{R T_{\mathrm{g}}}+\text { constant }
$$

where $T_{\mathrm{g}}$ is the transition temperature as a function of the heating rate $\phi$ in the thermal analysis. Fig. 2 shows the Kissinger plots for glass transition and crystallization of bulk $\mathrm{Fe}_{80} \mathrm{P}_{13} \mathrm{C}_{7}$ amorphous alloy specimens. The apparent activation energies for glass transition $E_{\mathrm{g}}$ and $E_{\mathrm{p}}$ can be determined to be 857 and $488 \mathrm{~kJ} / \mathrm{mol}$, respectively. In addition the glass transition temperature $T_{\mathrm{g}}$ and the crystallization temperature $T_{\mathrm{p}}$ can be determined to be 675 and $710 \mathrm{~K}$ from DSC curve at the heating rate of $0.33 \mathrm{~K} / \mathrm{s}$, respectively. 

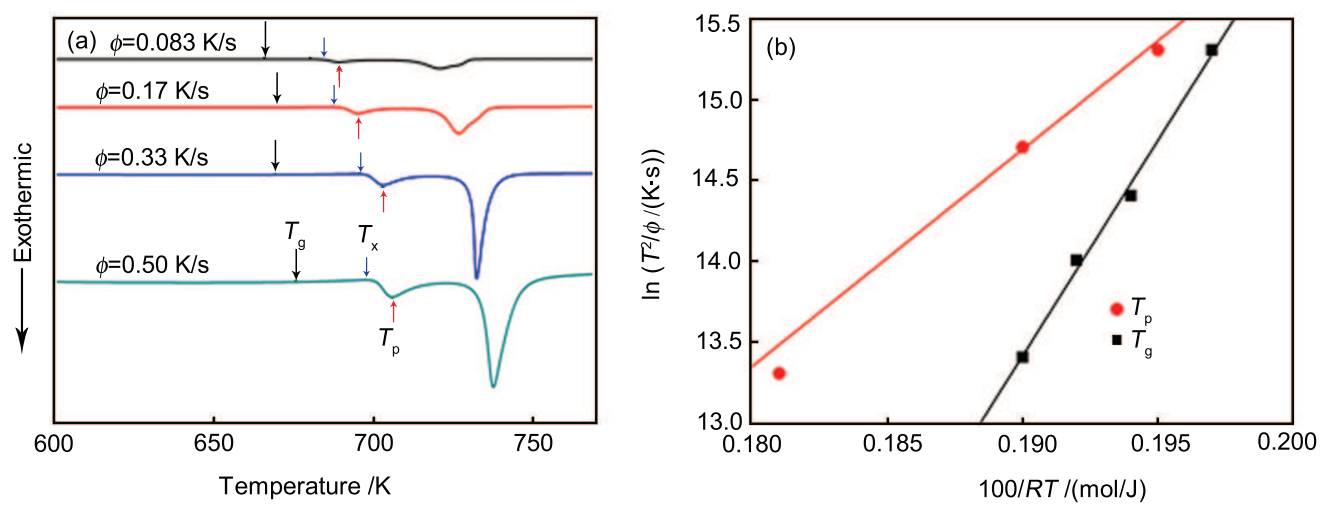

Fig. 2 DSC curves of as-prepared bulk $\mathrm{Fe}_{80} \mathrm{P}_{13} \mathrm{C}_{7}$ amorphous alloys with different heating rates $(\phi)(\mathrm{a})$ and the Kissinger plots for the glass transition $\left(T_{\mathrm{g}}\right)$ and crystallization $\left(T_{\mathrm{p}}\right)$ of bulk $\mathrm{Fe}_{80} \mathrm{P}_{13} \mathrm{C}_{7}$ amorphous alloy (b)

Here some different methods were used to determine $A, B$ and $T_{0}$ in Eq. (16) so as to establish the temperature dependence of the viscosity of $\mathrm{Fe}_{80} \mathrm{P}_{13} \mathrm{C}_{7}$ alloy in the undercooled liquid region. These methods arose from the different choices of $\eta$ or $E(T)$ at the different temperatures used.

\subsubsection{Method (a)}

By taking $\eta\left(T_{\mathrm{m}}\right)=5 \mathrm{~Pa} \cdot \mathrm{s}$ and $\eta\left(T_{\mathrm{g}}\right)=10^{12} \mathrm{~Pa} \cdot \mathrm{s}$ for $\mathrm{Fe}_{80} \mathrm{P}_{13} \mathrm{C}_{7}$ alloy together with the equation of $E_{\mathrm{g}}=\frac{R B T_{\mathrm{g}}^{2}}{\left(T_{g}-T_{0}\right)^{2}}$, the expression of $\eta(T)$ can be given by

$$
\eta(T)=7.3 \times 10^{-3} \exp \left(\frac{4681}{T-531}\right)
$$

\subsubsection{Method (b)}

By taking $\eta\left(T_{\mathrm{m}}\right)=5 \mathrm{~Pa} \cdot \mathrm{s}$ and $\eta\left(T_{\mathrm{g}}\right)=10^{12} \mathrm{~Pa} \cdot \mathrm{s}$ for $\mathrm{Fe}_{80} \mathrm{P}_{13} \mathrm{C}_{7}$ alloy together with the equation of $E_{\mathrm{p}}=\frac{R B T_{\mathrm{p}}^{2}}{\left(T_{p}-T_{0}\right)^{2}}$, the expression of $\eta(T)$ can be obtained as

$$
\eta(T)=6.0 \times 10^{-1} \exp \left(\frac{5313}{T-486}\right)
$$

\subsubsection{Method (c)}

By taking $\eta\left(T_{\mathrm{g}}\right)=10^{12} \mathrm{~Pa} \cdot \mathrm{s}$ for $\mathrm{Fe}_{80} \mathrm{P}_{13} \mathrm{C}_{7}$ alloy together with the equations of $E_{\mathrm{p}}=\frac{R B T_{\mathrm{p}}^{2}}{\left(T_{\mathrm{p}}-T_{0}\right)^{2}}$ and $E_{\mathrm{g}}=\frac{R B T_{\mathrm{g}}^{2}}{\left(T_{\mathrm{g}}-T_{0}\right)^{2}}$, the expression of $\eta(T)$ can be written as

$$
\eta(T)=3.3 \times 10^{5} \exp \left(\frac{704}{T-619}\right)
$$

\subsubsection{Method (d)}

By taking $\eta\left(T_{\mathrm{m}}\right)=5 \mathrm{~Pa} \cdot \mathrm{s}$ for $\mathrm{Fe}_{80} \mathrm{P}_{13} \mathrm{C}_{7}$ alloy together with the equations of $E_{\mathrm{p}}=\frac{R B T_{\mathrm{p}}^{2}}{\left(T_{\mathrm{p}}-T_{0}\right)^{2}}$ and $E_{\mathrm{g}}=\frac{R B T_{\mathrm{g}}^{2}}{\left(T_{\mathrm{g}}-T_{0}\right)^{2}}$, the expression of $\eta(T)$ can be written as

$$
\eta(T)=3.3 \times 10^{-1} \exp \left(\frac{1819}{T-585}\right)
$$

However, with Eq. (20) obtained by method (c), $\eta\left(T_{\mathrm{m}}\right)$ of the specimen will be given an unsubsistent large viscosity of $1.0 \times 10^{7} \mathrm{~Pa} \cdot \mathrm{s}$. Likewise, with Eq. (21) obtained by method $(\mathrm{d}), \eta\left(T_{\mathrm{m}}\right)$ of the specimen will be given an unsubsistent low viscosity of $2.0 \times$ $10^{8} \mathrm{~Pa} \cdot \mathrm{s}$. It is indicated that Eqs. (20) and (21) are not the plausible expression of the viscosity of the specimen. Only the expressions of $\eta(T)$ determined by method (a) and (b) were considered in the following discussion.

\subsubsection{Determination of $R_{\mathrm{c}}$ from TTT and CCT Curves}

Based on the above efforts, a TTT diagram corresponding to a volume fraction of $X=10^{-6}$, which is considered to be a just detectable concentration of crystals $^{[5]}$, can now be constructed. By substituting the different expressions of $\eta(T)$ obtained by using methods (a) and (b) and the different expressions of $\Delta G^{\mathrm{l}-\mathrm{s}}$ from Eq. (10) to Eq. (13), the corresponding TTT curves for $\mathrm{Fe}_{80} \mathrm{P}_{13} \mathrm{C}_{7}$ alloy were obtained. So the $R_{\mathrm{c}}$ for the glass formation of $\mathrm{Fe}_{80} \mathrm{P}_{13} \mathrm{C}_{7}$ alloy can be given by

$$
R_{\mathrm{c}} \approx \frac{T_{\mathrm{m}}-T_{\mathrm{n}}}{t_{\mathrm{n}}}
$$

where $T_{\mathrm{m}}$ is the melting temperature, $T_{\mathrm{n}}$ and $t_{\mathrm{n}}$ are the temperature and time corresponding to the nose of TTT curve, respectively. A more realistic estimate of $R_{\mathrm{c}}$ can be obtained from CCT curve instead of TTT curve. Based on the Scheil additivity rule ${ }^{[22]}$, CCT curves can be constructed from the corresponding TTT curves. Fig. 3 shows a few typical TTT (solid lines) and the corresponding CCT (dashed lines) curves of $\mathrm{Fe}_{80} \mathrm{P}_{13} \mathrm{C}_{7}$ alloy. As shown in Fig. 3, the $R_{\mathrm{c}}$ position of the nose of CCT curve moves down and back relative to that of the corresponding TTT curve. Thus the $R_{\mathrm{c}}$ determined from CCT curves using Eq. (22) are lower than those determined from TTT curves. The critical cooling rates are summarized in Table 1. From Table 1 it can be found that the $R_{\mathrm{c}}$ from CCT curves are about $1 / 3$ of that from TTT curves for all kinds of cases. 

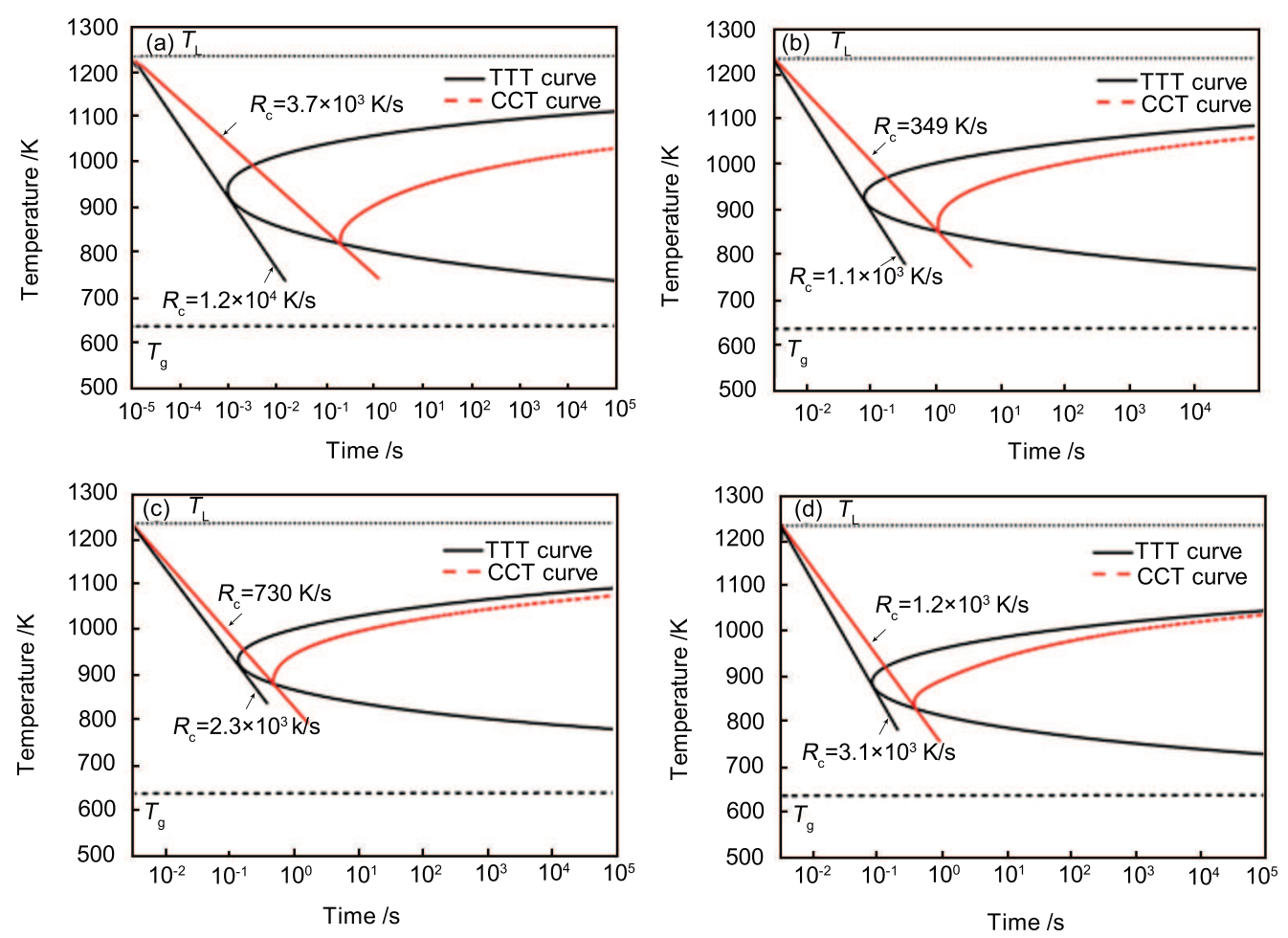

Fig. 3 TTT and CCT curves constructed by using the different Gibbs free energy obtained from Eq. (10) (a), Eq. (11) (b), Eq. (12) (c) and Eq. (13) (d) with the viscosity determined by method (a)

Table 1 The critical cooling rates $R_{\mathrm{c}}(\mathrm{K} / \mathrm{s})$ for the glass formation of $\mathrm{Fe}_{80} \mathrm{P}_{13} \mathrm{C}_{7}$ alloy determined from TTT and CCT curves which are constructed with the $\Delta G^{1-\mathrm{s}}$ that calculated by Eqs. (10), (12), (13) and (14) and the $\eta(T)$ determined by method (a) and (b)

\begin{tabular}{|c|c|c|c|c|c|}
\hline \multirow[t]{2}{*}{ Corresponding curve } & & \multicolumn{4}{|c|}{$\begin{array}{l}R_{\mathrm{c}}(\mathrm{K} / \mathrm{s}) \text { constructed with the } \\
\text { different expressions of } \Delta G^{\mathrm{l}-\mathrm{s}}\end{array}$} \\
\hline & & Eq.(10) & Eq.(12) & Eq.(13) & Eq.(14) \\
\hline TTT & $\eta(T)$ determined by & $1.2 \times 10^{4}$ & $1.1 \times 10^{3}$ & $2.3 \times 10^{3}$ & $3.1 \times 10^{3}$ \\
\hline $\mathrm{CCT}$ & method (a) & $3.7 \times 10^{3}$ & 349 & 730 & $1.2 \times 10^{3}$ \\
\hline TTT & $\eta(T)$ determined by & $2.4 \times 10^{4}$ & $3.1 \times 10^{3}$ & $2.8 \times 10^{3}$ & $5.4 \times 10^{3}$ \\
\hline $\mathrm{CCT}$ & method (b) & $7.7 \times 10^{3}$ & $1.0 \times 10^{3}$ & 798 & $1.8 \times 10^{3}$ \\
\hline
\end{tabular}

\subsection{Barandiaran-Colmenero's method}

By considering the liquid-solid transformation behaviour under non-isothermal conditions, Barandiaran and Colmenero ${ }^{[8]}$ have obtained a relation which enables the critical cooling rate, $R_{\mathrm{c}}$, to be evaluated from thermal analytical measurements. The relation is

$$
\ln R_{\mathrm{r}}=\ln R_{\mathrm{c}}-\frac{C}{\left(T_{\mathrm{L}}-T_{\mathrm{XC}}\right)^{2}}
$$

where $R_{\mathrm{r}}$ is the cooling rate, $T_{\mathrm{L}}$ is the offset temperature of fusion, and $T_{\mathrm{XC}}$ is the onset temperature of solidification and $C$ is a constant. By measuring $T_{\mathrm{L}}$ upon melting at a constant heating rate and $T_{\mathrm{XC}}$ upon cooling at different cooling rates $R_{\mathrm{r}}$ using thermal analytical techniques, the $R_{\mathrm{c}}$ for the glass formation can be determined from the plot of $\ln R_{\mathrm{r}}$ against $1 /\left(T_{\mathrm{L}}-T_{\mathrm{XC}}\right)^{2}$.

\section{Results and Discussion}

Most recently, bulk magnetic $\mathrm{Fe}_{80} \mathrm{P}_{13} \mathrm{C}_{7}$ glassy alloy rods with a maximum diameter of $2.0 \mathrm{~mm}$ had been prepared by fluxing technique and novel Jquenching technique ${ }^{[3]}$. The cooling rate of the specimen with the diameter of $2.0 \mathrm{~mm}$ in J-quenching technique can be estimated to be below $10^{3} \mathrm{~K} / \mathrm{s}^{[4]}$. The $R_{\mathrm{c}}$ for the glass formation of an alloy should be determined based on homogenous nucleation mechanism. However heterogeneous impurities cannot be avoided entirely under the laboratory conditions. So the $R_{\mathrm{c}}$ for the glass formation of $\mathrm{Fe}_{80} \mathrm{P}_{13} \mathrm{C}_{7}$ alloy should be adequately lower than $10^{3} \mathrm{~K} / \mathrm{s}$. Based on the above estimation, it can be decided which the calculated $R_{\mathrm{c}}$ in Table 1 are reasonable and which the expressions of and obtained using the different methods are appropriate for $\mathrm{Fe}_{80} \mathrm{P}_{13} \mathrm{C}_{7}$ alloy.

\subsection{Uhlmann's method}

\subsubsection{Effect of the difference of Gibbs free energy between solid and liquid}

At first these resultant $R_{\mathrm{c}}$ determined by CCT 
curves using the different expressions of and $\eta(T)$ obtained by method (a) in Table 1 are investigated. It indicates that $R_{\mathrm{c}}$ obtained using the difference expressions from Eq. (10) to Eq. (13) can vary within two orders of magnitude. And only the results for Eq. (11) and (12) are placed in the reasonable range. Comparatively, the result obtained by Eqs. (11) is more suitable for $\mathrm{Fe}_{80} \mathrm{P}_{13} \mathrm{C}_{7}$ alloy than that with Eq. (12). Similar results have also been found in those cases as using $\eta(T)$ obtained by method (b).

In fact all equations from Eqs. (10) to (13) are approximated expressions of Eqs. (9), (11) and (12) are obtained from the same hypothesis, therefore, which should appropriate for determining $\Delta G^{\mathrm{l}-\mathrm{s}}$ for Fe-based alloys. Eq. (13) is proposed based on the experimental data of $\mathrm{Zr}_{57} \mathrm{Cu}_{15.4} \mathrm{Ni}_{12.6} \mathrm{Al}_{10} \mathrm{Nb}_{5}$ alloy and seems not to be suitable for Fe-based alloys. Cai et al. ${ }^{[23]}$ proposed that the expressions of $\Delta G^{\mathrm{l}-\mathrm{s}}$ of the amorphous alloys can be reasonably chosen based on the reduced glass transition temperature $T_{\mathrm{rg}}=T_{\mathrm{g}} /$ $T_{\mathrm{L}}$, which is the most common empirical criterion for quantifying glass forming ability (GFA) of amorphous alloys. They considered all kinds of the expressions of $\Delta G^{\mathrm{l}-\mathrm{s}}$ and proposed that Eq. (11) and (12) are suitable for amorphous alloys with the smallest $T_{\mathrm{rg}}$. Compare with other amorphous alloys, Fe-based amorphous alloys have lower GFA and smaller $T_{\text {rg }}$.

\subsubsection{Effect of the viscosity}

Compare with the resultant $R_{\mathrm{c}}$ determined by CCT curves using $\eta(T)$ obtained by method (a) and (b) in Table 1, these results are not largely deviate from each other for the different expressions of $\Delta G^{\mathrm{l}-\mathrm{s}}$ and the $R_{\mathrm{c}}$ with $\eta(T)$ determined by method (a) are lower than that with $\eta(T)$ determined by method (b). Comparatively, method (a) gives a more realistic estimate for $\eta(T)$ of $\mathrm{Fe}_{80} \mathrm{P}_{13} \mathrm{C}_{7}$ alloy than method (b).

In fact the choice of the expression of $\eta(T)$ is crucial for the calculation of $R_{\mathrm{c}}$ in Uhlmann's method. However, due to the lack of both the experimental data and the theoretical models about the dependence of viscosity on temperature of metallic glasses, especially Fe-base metallic glasses, not too much attempts to determine the dependence of viscosity on temperature had been investigated in this paper. In addition, it is assumed that the dependence of viscosity of the alloy on temperature accords with Vogel-Fulcher's expression in both method (a) and method (b). However it had been pointed out in many studies ${ }^{[24,25]}$ that a Vogel-Fulcher's expression with one set of constants may be unsuitable for a metallic glass to fit the whole range of viscosities from the $T_{\mathrm{g}}$ to $T_{\mathrm{m}}$. In a word, further progress on the viscosity of metallic glasses is needed in order to exactly estimate the $R_{\mathrm{c}}$ for the glass formation of metallic glasses, especially Fe-based metallic glasses.

\subsection{Barandiaran-Colmenero' method}

The DTA curves of the $\mathrm{Fe}_{80} \mathrm{P}_{13} \mathrm{C}_{7}$ bulk amorphous alloy at the cooling rates of $0.083,0.17,0.33$ and $0.50 \mathrm{~K} / \mathrm{s}$ are shown in Fig. 4(a). The plot of $\ln R_{\mathrm{r}} v s$. $1 /\left(T_{\mathrm{L}}-T_{\mathrm{XC}}\right)^{2}$ obtained using the data deduced from the DTA measurements is shown in Fig. 4(b). Thus the $R_{\mathrm{c}}$ for the glass formation of the $\mathrm{Fe}_{80} \mathrm{P}_{13} \mathrm{C}_{7}$ alloy is determined to be $0.49 \mathrm{~K} / \mathrm{s}$ based on Eq. (23). The resultant $R_{\mathrm{c}}$ is shockingly low. Until now few works about the calculation of $R_{\mathrm{c}}$ for Fe-based alloys using Barandiaran-Colmenero' method have been reported. Based on Barandiaran-Colmenero's method, the $R_{\mathrm{c}}$ of $\mathrm{Fe}_{61} \mathrm{Co}_{5} \mathrm{Zr}_{8} \mathrm{Y}_{2} \mathrm{Cr}_{2} \mathrm{Mo}_{7} \mathrm{~B}_{15}^{[26]}, \mathrm{Fe}_{48} \mathrm{Cr}_{15} \mathrm{Mo}_{14} \mathrm{C}_{15} \mathrm{~B}_{6} \mathrm{Y}_{2}$ and $\mathrm{Fe}_{41} \mathrm{Co}_{7} \mathrm{Cr}_{15} \mathrm{Mo}_{14} \mathrm{C}_{15} \mathrm{~B}_{6} \mathrm{Y}_{2}^{[27]}$ alloys are determined to be $37,11.2$ and $6.5 \mathrm{~K} / \mathrm{s}$, respectively. It is indicated that the resultant $R_{\mathrm{c}}$ for Fe-based alloys using Barandiaran-Colmenero' method are all quite low. However, it is reported that the $R_{\mathrm{c}}$ for the glass formation for Zr-based determined using Barandiaran-Colmenero's method are in the orders of $10 \mathrm{~K} / \mathrm{s}^{[28,29]}$. It is well known that the glass-forming ability (GFA) of Zr-based alloy is much larger than that of Fe-based alloy. So it seems that BarandiaranColmenero's method is not suitable for determination of the $R_{\mathrm{c}}$ for the glass formation for Fe-based alloy. The $R_{\mathrm{c}}$ for Fe-based alloys are very large and only the dozens of cooling rates using in the measurement of DTA cannot reflect the crystallization kinetic behavior of Fe-based alloy under the large undercooling well. This may lead to the failure of BarandiaranColmenero's method to determine the $R_{\mathrm{c}}$ for the glass formation for these alloys with a low GFA just like Febased alloy.
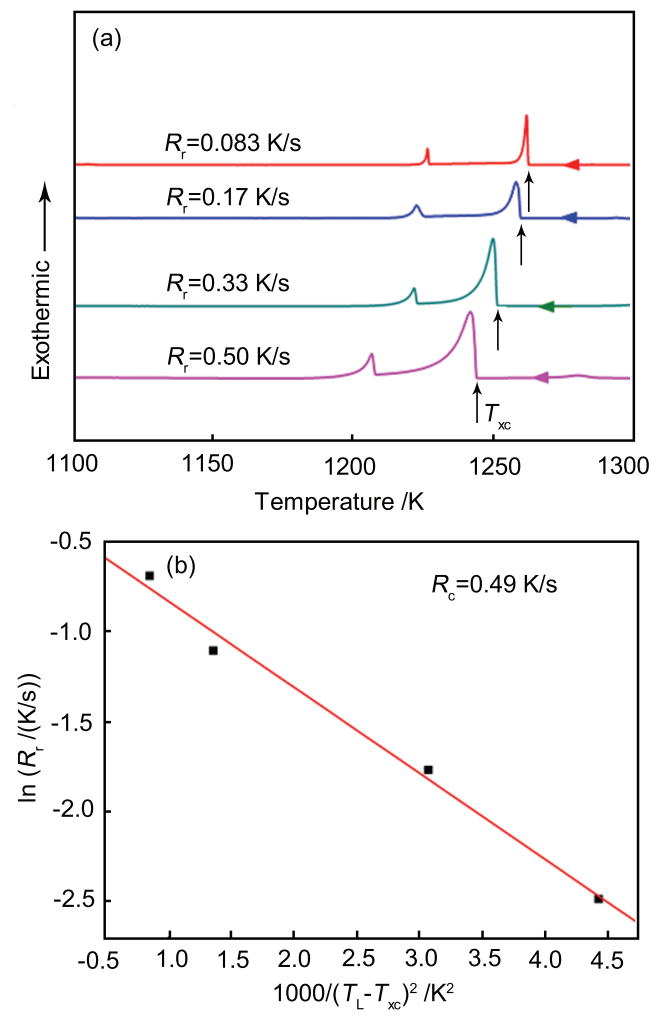

Fig. 4 DTA cooling curves of $\mathrm{Fe}_{80} \mathrm{P}_{13} \mathrm{C}_{7}$ alloy at various cooling rates $\left(R_{\mathrm{r}}\right)(\mathrm{a})$ and the critical cooling rate plot of $\ln R$ vs. $1 /\left(T_{\mathrm{L}}-T_{\mathrm{XC}}\right)^{2}$ (b) 


\section{Conclusions}

The $R_{\mathrm{c}}$ for the glass formation of $\mathrm{Fe}_{80} \mathrm{P}_{13} \mathrm{C}_{7}$ alloy has been estimated using both Uhlmann's method and Barandiaran-Colmenero's method. In Uhlmann's method, all kinds of the expressions of $\Delta G^{\mathrm{l}-\mathrm{s}}$ and $\eta(T)$ determined using the different modes and methods had been investigated. It is indicated that Eq. (12) for $\Delta G^{\mathrm{l}-\mathrm{s}}$ and methods (a) for $\eta(T)$ give the best estimation for the $R_{\mathrm{c}}$ for the glass formation of $\mathrm{Fe}_{80} \mathrm{P}_{13} \mathrm{C}_{7}$ alloy and the resultant $R_{\mathrm{c}}$ is $349 \mathrm{~K} / \mathrm{s}$ determined from CCT curve. The calculated result accords with our experimental result ${ }^{[3]}$ and meantime it is indicated that the heterophase impurities have been controlled well in J-quenching technique. In addition, the $R_{\mathrm{c}}$ for the glass formation of $\mathrm{Fe}_{80} \mathrm{P}_{13} \mathrm{C}_{7}$ alloy has also been determined to be $0.49 \mathrm{~K} / \mathrm{s}$ based on Barandiaran-Colmenero' method. But this resultant $R_{\mathrm{c}}$ is unreasonable low and it shows that BarandiaranColmenero' method is not suit to Fe-based alloy.

\section{Acknowledgements}

This work was supported by the National Natural Science Foundation of China (No. 50861007), the Project of Supporting Xinjiang Uyghur Autonomous Region by Science and Technology (No. 201191203) and the Opening Subject from State Key Laboratory of Powder Metallurgy in Central South University.

\section{REFERENCES}

[1] P. Duwez and S.C.H. Lin, J. Appl. Phys. 38 (1967) 4096.

[2] A. Takeuchi and A. Inoue, Mater. Sci. Eng. A 304306 (2001) 446.

[3] Q. Li, J.F. Li, P. Gong, K.F. Yao, J.E. Gao and H.X. Li, Intermetallics 26 (2012) 62.

[4] Q. Li, Metall. Mater. Trans. B 40 (2009) 405.

[5] D.R. Uhlmann, J. Non-Cryst. Solids 7 (1972) 337.
[6] W.H. Wang, C. Dong and C.H. Shek, Mater. Sci. Eng. R 44 (2-3) (2004) 45.

[7] A. Inoue and A. Takeuchi, Int. J. Appl. Glass Sci. 1 (2010) 273.

[8] J.M. Barandiaran and J. Colmenero, J. Non-Cryst. Solids 46 (1981) 277.

[9] K.F. Kelton, Solid State Phys. 45 (1991) 75.

[10] J.W. Christian, The Theory of Transformations in Metals and Alloys, Pergamon, Oxford, 2002, P. 483.

[11] J.D. Hoffman, J. Chem. Phys. 29 (1958) 1192.

[12] C.V. Thompson and F. Spaepen, Acta Metall. 27 (1979) 1855.

[13] Kirit N. Lad, K.G. Raval and A. Pratap, J. Non-Cryst. Solids 334 (2004) 259.

[14] X.L. Ji and Y. Pan, J. Non-Cryst. Solids 353 (2007) 2443.

[15] D.A. Porter and K.E. Easterling, Phase Transformation in Metals and Alloys,2nd Ed., Chapman \& Hall, London, 1992, p.70.

[16] H.S. Chen, J. Non-Cryst. Solids 27 (1978) 257.

[17] H.S. Chen, Appl. Phys. Lett. 29 (1976) 12.

[18] H.S. Chen and D. Turnbull, J. Chem. Phys. 48 (1968) 2560.

[19] B.G. Bagley and E.M. Vogel, J. Non-Cryst. Solids 18 (1975) 29.

[20] K. Matusita, T. Komatsu and R. Yokota, J. Mater. Sci. 19 (1984) 291.

[21] H.E. Kissinger, Anal. Chem. 29 (1957) 1702.

[22] E. Scheil, Arch. Eisenhuttenwes. 8 (1935) 565.

[23] A.H. Cai, X. Xiong and Y. Liu, J. Non-Cryst. Solids 356 (2010) 1498.

[24] A. Peker and W.L. Johnson, Mater. Sci. Eng A 179 (1994) 173.

[25] A. Inoue, T. Zhang and T. Masumoto,. J. Non-Cryst. Solids 156 (1993) 473.

[26] Q.J. Chen and H.B. Fan, J. Alloys Compd. 407 (2006) 125.

[27] J. Shen, Q.J. Chen, J.F. Sun, H.B. Fan and G. Wang, Appl. Phys. Lett. 86 (2005) 151907.

[28] H.H. Hng, Y. Li, S.C. Ng and C.K. Ong, J. Non-Cryst. Solids 208 (1996) 127.

[29] Z.P. Lu, H. Tan, S.C. Ng and Y. Li, Scr. Mater. 42 (2000) 667. 